\title{
Breaking out of silos: explaining cross-departmental interactions in two European bureaucracies.
}

Francesca Pia Vantaggiato, Hussein Kassim, Sara Connolly

Abstract: The view that silos are endemic in organisations in general and the European Civil Service in particular has become increasingly widespread. Yet, silos are rarely investigated theoretically or empirically. What is a silo? What are the individual and organisational factors associated with silos? We propose a functionalist approach to silo definition and identification, which links individual and organisational tasks to expected intra-organisational interactions: we operationalize silos as clusters of employees lacking communication with other parts of the organisation, and analyse civil servants and departments as bipartite networks of communication using stochastic blockmodelling. We explore the existence of silos in two European bureaucracies, which differ in mission, size and workforce composition: the European Commission and the General Secretariat of the Council. We do not find evidence of silo-ization in either bureaucracy, but rather task-based patterns of interaction. Our approach can be extended to include other theoretical perspectives, e.g. socialization effects.

Keywords: administrative silos, blockmodels, coordination, European Commission, General Secretariat of the Council 


\section{Introduction}

For more than two decades, pessimism about the possibility of interaction across organisational barriers has become increasingly widespread. In both academic and practitioner-oriented literatures, silos are presented as a pernicious but omnipresent feature of organizations in general and public administration in particular (Tett 2015). They lead to inefficiency -- suboptimal decision making, poor policy delivery, and weak performance (Hood 1974, Rhodes 1994, Bach and Wegrich 2019). Yet, key questions remain unaddressed. The first concerns simple conceptual clarity. What is a silo? Few authors define the term, even when claiming that the concept has direct lineage to classic canons of modern bureaucracy and organisation. Second, what prompts civil servants to reach beyond their desks and interact with colleagues in other offices and departments? Third, what organisational and individual-level characteristics are associated with the presence of silos? The literature is largely silent on these matters. The existence of silos is often invoked to justify changes in public policy or the enactment of administrative reform. Yet, such claims are rarely accompanied by empirical evidence establishing silos as the cause of the claimed effects in performance or delivery.

This article takes a first step to addressing the lack of conceptual clarity and empirical analysis concerning silos in bureaucratic organizations. We develop a functionalist argument that assesses the presence of silos in bureaucratic organizations based on individual and organisational tasks. We operationalize silos as clusters of employees that lack interaction with other parts of the organisations beyond their immediate co-workers. Although the presence of communication between civil servants and departments does not in itself guarantee successful coordination, communication is a minimum requirement for the exchange of information necessary for coordination (Van de Ven and Gordon 1984, Enemark, McCubbins et al. 2014). 
Therefore, we investigate the frequency of communications between individual employees across the organization based on their job task.

We draw on the assertion made by Gulick (1937) that the division of labour is the starting point for understanding organizations. Hence, we distinguish between the tasks of individual workers according to two of Gulick's principles of departmentalization: purpose and process. With purpose-oriented tasks, such as developing policy or providing policy advice, what is accomplished matters more than how. By contrast, with process-oriented tasks - for example, translation, security, legal services, and administration - it is method and procedure that count (Gulick 1937). Organisational departments need to establish which combination of workers is appropriate to their primary organising principle. The same logic applies to whole organisations, which can be organised primarily in terms of purpose or process (Hammond 1990).

Therefore, besides individual employees' job task, we focus on two organizational variables, which are often correlated in bureaucratic organisations: mission and size. Organisations with purpose-based missions (e.g. policy-making) tend to be larger and are expected to be more prone to silo-ization than smaller organisations with process-based mission (e.g. administrative support) (Blau 1970). We operationalise our framework by performing a comparative analysis of two different European bureaucracies in terms of size, mission and workforce composition - the European Commission and the General Secretariat of the Council ('GSC' or 'Council Secretariat'). The Commission is a policy-making (therefore, purpose-based) organisation with a workforce of 30,000; the GSC is a small administrative (i.e. process-based) organisation with 3,000 employees. We rely on stochastic blockmodelling analysis of the bipartite networks resulting from the ties linking individual employees to different departments. Comparing and contrasting the variables associated with patterns of communication within these two very 
different bureaucracies allows drawing stronger conclusions about their more general applicability.

Existing literature on the European Commission argues that departments organised by purpose (i.e. policy DGs) exhibit strong within-unit coordination, but low cross-unit coordination, which leads to silos (Trondal 2011, 2017). We derive our main working hypothesis from this claim and proceed quantitatively to assess the presence of silos in the Commission and the GSC. Unlike existing literature (Coombes 1970, Cram 1994, Cini 1995, Hartlapp et al 2014, Trondal 2017), however, we focus on the individual, rather than the departmental (DG) level of analysis. Individuals interact, not entire departments. Examination of individual-level behaviour makes it possible to capture exactly who is interacting, where and why. Since each DG comprises a mix of specialists with different tasks (some purpose-based, others processrelated) and different lines of communication to different parts of the organisation, investigation at the departmental level would make it impossible to differentiate between these different groups, even though they might behave differently. An additional reason for the individual-level focus is that, whereas interaction between departments is likely to be procedural, contact between individuals can be motivated by a diverse range of intentions, including getting the job done. Especially when it is reported, individual-level communication is potentially more meaningful, more wide-ranging, and less likely than inter-departmental interaction to be merely formalistic. The individual-level analysis also provides a pattern of intra-organisational interaction that could challenge, confirm, complement, or qualify the picture derived from the more traditional inter-departmental level approach.

We find that, in both bureaucracies, individuals with purpose-based tasks (e.g. providing policy advice) frequently interact beyond their departments, while bureaucrats with certain processbased tasks (e.g. primarily, translation) do not. Our findings at organisational level are more 
ambivalent. Employees in the European Commission -- a large bureaucratic organisation that is organised primarily according to purpose - appear relatively more siloed than the GSC -- a smaller bureaucracy organised according to process. This finding is in keeping with expectations concerning size and mission. However, in neither organisation do we identify levels of siloization sufficient to disrupt the organisational mission.

From a policy perspective, our framework makes it possible to verify the presence of silos empirically. Where silos can be excluded, the causes of poor performance need to be found elsewhere. Attention biases, political agendas, and lack of resources have all been found to hamper public service delivery, in the European Union and elsewhere (Bach and Wegrich 2019). Our framework can be fruitfully expanded through further theoretical and empirical development. Studies investigating other mechanisms whereby bureaucracies might develop silos - e.g. based on socialisation approaches - represent a promising avenue of future research.

\section{Silos in context: new and old usages compared.}

In public policy and administration, silos are frequently reported as the cause of poor organisational performance or policy failure (Bundred 2006, Rayner and Howlett 2009, Vince 2015). Yet, the organisational challenges associated with task specialisation are not new (Gregory 2006). The assumption that bureaucracies would be internally differentiated dates to Weber (1922) and Gulick (1937), while the assumption that organisations are essentially pluralistic was a preoccupation of mid-century scholarship in the field. In at least three subliteratures -- on 'bureaucratic politics', 'policy coordination', and 'turf politics' (see t'Hart and Wille 2012 for a review) -- authors take as a given that, on whatever organizational principle work is divided, organization by task specialization inevitably gives rise to a plurality of 
interests and outlooks, and therefore competition and conflict. However, interdependence usually makes these differences negotiable with more or less effort. Provided that the right structures, strategies or mechanisms are in place, the different parts of the organisation or system can be encouraged, persuaded or compelled to work together (Heims 2019). At the same time, scholars in these literatures recognise the cost in effort and time of managing intraand inter-organizational interaction (Coase 1937, Pressman and Wildavsky 1973, Seidman 1997, Peters 1998).

In these literatures, silos are an extreme case -- the result of weak or absent coordination among organisational units. There is a voluminous scholarship on coordination, the challenges it poses and how it might be addressed across a range of public sector organisations from the wholeof-government to individual bureaucracies (Bouckaert et al 2010). The pursuit of effective coordination has been likened to the search for the philosopher's stone (Peters 2015, 2018).

The debate about coordination and organisational fragmentation was revived anew in the literature on the new public management (NPM) (Richards and Smith 2006), with its emphasis on managerialism, differentiation, and specialisation aimed at improving public service delivery, though subsequently criticised for creating excessive fragmentation, producing disconnected and redundant policy programmes. Later initiatives, 'joined-up government' (Bogdanor 2005) and 'whole of government' (Christensen and Lagreid, 2007), enacted to counteract the effects of NPM reforms, only confirmed the classic tenet of organisation theory that specialisation and differentiation increase the need for coordination (Thompson 1967).

We question the conviction that silos are everywhere (O'Flynn et al. 2013, Trondal 2012) and posit that 'what is termed siloization is - like fragmentation - an age-old bureaucratic tendency' (Gregory 2006). We argue that 'silos' needs to be restored of its original sense if the concept is to retain analytical value. Our concern is motivated not only by scientific anxieties over 
'conceptual stretching' (Sartori 1970), but also about possible misuse of the term. Silos are invoked to shift blame to structures or substructures and, not infrequently, to legitimate reform of administrations and organisation. In absence of definitional clarity and a clear diagnostic framework, such rhetoric or action might be unjustified, and the real source of the problem undetected.

As Page (2005) observed in the case of 'joined-up' government reforms, the silos in question were often not specified. Nor was proof provided that they were the source of the problems that reform was intended to correct. Consequently, reformers overstated what could be achieved and took a 'one-size-fits-all' approach to improving interaction across organisational boundaries, when in fact 'a clear and sharp division of organisational labour' may be appropriate, especially when the issues to be tackled follow the boundaries of organisational units and do not cut across them (Laegreid et al 2016).

We contend that silos exist when intra-organisational communication has broken down, resulting in the isolation of parts of the organisation. Silos emerge in conditions where internal interaction is not merely difficult or problematic, but absent. The defining feature for silos to be present is when the effort of departments 'to enhance their specific contributing functions is allowed to prevail, this impedes policy coordination and blocks the flows of information needed to make full use of organizational capabilities' (emphasis added) (t'Hart and Wille 2012). We build on existing understandings in the literature where siloization results from a lack of intra-organisational communication (Laegreid et al 2015, Bouckaert et al 2016). For Bacharach and Aiken (1977: 365), 'the daily routine of organisations entails information exchange and coordination. To the extent that both activities are dependent upon communication networks, communication becomes a plausible focus for comparative organizational analysis'. More recently, O'Flynn et al (2013) report that horizontal 
communication compensates for siloization and departmentalization in Norway's central government. In this spirit, this paper compares intra-organisational communication patterns within two different bureaucracies of the European Civil Service.

\section{Communication inside the Commission and the Council Secretariat: conflict or cooperation?}

We advocate an empirical approach to the study of intra-organizational interaction. We take the European Commission and the GSC as case studies. A brief description of the salient features of each is provided in the online appendix. These organizations have been chosen for two reasons: first, because the EU bureaucracy has historically been presented as fragmented and silo-ridden (Coombes 1970; see also Spierenburg 1979 and Cini 1996); and second, because the two bodies differ significantly in mission, size and workforce composition, which enables us to test propositions from the organisations literature (Gulick 1937, Blau 1970, Bacharach and Aiken 1977).

The following discussion aims to advance understanding of these organizations in three ways. First, it provides the first analysis of individual-level interaction inside two EU bureaucracies. Although there is an impressive literature on coordination (Coombes 1970, Trondal 2011, Kassim et al 2013, Hartlapp et al 2014), existing scholarship has focused on interaction at unit or sub-unit levels alone. Second, the Council Secretariat has a reputation for preferring to remain in the shadows (Christiansen 2002), and as a result attracted limited scholarly attention. The body of literature that does exist highlights the Secretariat's key advisory role to national delegations who meet in the Council at official, ambassadorial and ministerial level, its function in preserving institutional memory, and its importance as an authority on EU law 
(Hayes-Renshaw and Wallace 2006), as well as the part it plays in treaty reform and negotiation. It also discusses the GSC's acquisition of new tasks, its integration of previously separate secretariats, the loss of foreign policy responsibilities following the Lisbon Treaty, and the creation of the permanent Presidency of the European Council. These developments have led to frequent re-organization of activities and a marked increase in staff resources whose integration and collaboration has proven difficult (Christiansen 2002). Both the collaboration challenges identified by Christiansen (2002) and the multiplication of the GSC's tasks suggest the presence of silos. However, these assertions have never been tested empirically.

Third, scholars have disputed internal integration in the Commission. The Commission was historically depicted as silo-ridden (Coombes 1970, Spierenburg 1979, Cram 1994, Peterson 1995, Cini 1996, Egeberg and Trondal 2016). Authors argued that, in the absence of strong central political control, the Commission's departments were self-governing 'baronies' or 'fiefdoms' that set their own priorities (Coombes 1970). That image has been challenged in recent accounts, which highlight how the strengthening of the Commission Presidency has made coordination and coherent action possible (Hartlapp et al 2014, Kassim 2012, Kassim et al 2013, Kassim et al 2016). The co-existence of these opposite perspectives - one emphasising the success of administrative integration reforms in fostering coordination (Kassim et al 2013, Hartlapp et al 2014), the other asserting that integration 'merely coexists with silo-ization of the Commission administration' (Trondal 2017, p. 80) - urges theoretical definition and empirical analysis.

Gulick (1937) argued that every employee in a bureaucracy is characterised by four organisational elements: the purpose the worker is serving, the process they are using, the clientele they serve, and the place where they render that service. Whenever employees in a departmental unit do not share all of the four, a decision needs to be made as to the primary 
element characterising the unit. Drawing on Gulick (1937), Trondal (2011) distinguishes between process-oriented (the Secretariat General) and purpose-based units (Directorate General for Trade) within the European Commission. He contends that, while the former prioritise the benefit of the organization as a whole and therefore attempt to foster internal collaboration, the latter units pursue departmental interests and are driven by a logic of portfolio that leads to silo thinking (Trondal 2017).

Drawing on extensive data gathered at individual level, we investigate intra-organisational communication within the European Commission and the GSC. Differently from existing literature, we eschew the temptation of attributing patterns of silo-ization (Trondal 2011, Trondal 2017) to entire DGs in either organisation. This approach implicitly assumes that all employees within a DG perform the same tasks and have similar professional goals. In reality, all DGs are internally heterogeneous, comprising individuals with both purpose- and processbased tasks. The relative isolation of the former type of employee across the organisation, we argue, would constitute grounds for concern about the presence of silos. Isolation of employees performing process-based tasks is only likely for those tasks that do not require extensive interaction with others (e.g. translation).

\section{Internal interaction in two parts of the EU administration: silos or business as usual?}

Following Page (2005), interaction across individuals and departments may vary, reflecting the different tasks performed and whether they necessitate high, low or no communication. From Trondal $(2011,2017)$, we should expect that silos exist when employees possessing purposebased tasks (e.g. policy analysis and advice) do not interact with colleagues beyond their 
immediate co-workers. Our first hypothesis concerning the presence of silos within a bureaucratic organisation, therefore, is:

H1: If silos exist within a bureaucratic organisation, a proportion of employees with purposeoriented responsibilities (such as policy analysis and advice) are less likely to be in frequent communication with colleagues beyond their immediate co-workers.

Employees whose tasks are process-based (e.g. coordination and administration) are expected to frequently communicate across the organization to fulfil their tasks. Some process-based tasks may not require extensive regular cross-departmental communication (e.g. translation services); hence, lack of intra-organisational communication for these employees would not constitute grounds for concern. The specific proportion of silo-ed employees that would be worrying is unspecified, because it depends on the characteristics of the administration in question and of the bureaucratic system it exists in.

Gulick's logic can be applied to whole organisations, to the extent that they are organised primarily around purpose or process (Hammond 1990). Translating the logic of purpose and process to the macro level of the organisation, we expect that policy-oriented organizations are more prone to silo formation than those that are support-oriented. Where an organization's mission is mainly to provide administrative support, the existence of silos is less likely and regular communication across different units can be expected (Blau 1970). The European Commission has major policy responsibilities, which require its staff to have the expertise and skills necessary to initiate, oversee and enforce policy. Therefore, it employs a high proportion of policy specialists in its workforce: $63 \%$ of Commission staff work in DGs with responsibilities for developing policy, managing programmes or regulation. By contrast, the GSC is responsible for organizing and supporting meetings and negotiations of the European Council and the Council of the European Union; therefore, it employs a high proportion of 
generalists, who are focused on logistics $(66 \%$ of GSC staff work in DG A, responsible for administration, logistics, security and translation). The emphasis on organisational mission is tied to considerations of organisational size. Larger organizations, whether public or private, are more complex and differentiated (Blau 1970, Blau 1972). However, the administrative component decreases in relative terms as size increases (Anderson and Warkov 1961, Blau 1970). Increased size increases the number of similar activities carried out within organizational sub-units, which eventually reduces the amount of administration required to coordinate them (Blau and Schoenherr 1971). Arguably, this leads to sub-units that scarcely interact. Conversely, in smaller organizations the relative size of the administrative component tends to be larger, leading to closer supervision and coordination across sub-units. Sub-units interact more often, therefore reducing the scope for the emergence of silos. Although organisational mission and size are analytically different characteristics, they are likely to covary, particularly for bureaucratic organisations where different units perform broadly similar sets of activities. These considerations prompt us to incorporate both mission and size in our second hypothesis under the heading of purpose and process:

H2: The presence of silos is more likely in public bureaucracies organised on the basis of purpose than in public bureaucracies organised on the basis of process.

\section{Data and method}

Most scholarly work on administrative silos relies predominantly on evidence from documentary research and interviews. Documentary analysis is extremely important in mapping processes and procedures, as Hartlapp et al (2014) demonstrate in their landmark study, while interviews allow researchers to gauge the perceptions of insiders and draw on their 
lived experience. However, if the aim is to map interactions in order to ascertain whether silos are present within an organisation, a large- $\mathrm{N}$ analysis is indispensable to developing an overview of communication patterns across intra-organisational boundaries.

This analysis uses data derived from surveys administered respectively in the European Commission and the General Secretariat of the Council in 2014 and 2016. Surveys were distributed to all staff, a total of 31,280 European Commission employees and 3,190 GSC employees. The achieved samples were 5,545 respondents in the Commission and 1,356 respondents in the GSC.

Both surveys asked respondents to report the frequency of the communications they have with units and departments across the organization in order to do their job. This emphasis on the communications that they need to have in order to adequately fulfil their tasks is important. Reply options mirrored the hierarchical organisational levels and ranged from co-workers (e.g. colleagues in my unit, my line manager, colleagues in my directorate) to colleagues in other DGs to central bodies (e.g. Secretary General or Legal Service). We used a common system to code the reply options, with higher values indicating a higher frequency of contact (see appendix) ranging from 'daily contact' to 'never'.

Analyses were limited to respondents who had provided full answers to these questions, and complete information as concerned the DG in which they worked, their tasks and their role. This considerably reduced the number of respondents in the two datasets -- to 2,711 (out of 2,734 respondents on administrator (ADR) contracts who were asked this question) from the Commission and 919 (out of 1,356) from the Council Secretariat - as the surveys were administered to all staff categories. ${ }^{\text {i }}$ These samples are broadly representative of the respective populations for each organization in terms of roles covered, as well as levels of engagement with their work ${ }^{\mathrm{ii}}$. 
Since both organisations are hierarchical, very high frequency interactions are only likely at departmental level. These priors are confirmed by descriptive statistics: average rates of interaction within units are 4.81 and 4.56 but across DGs they are 3.07 and 2.19 in the Commission and GSC respectively $(0=$ never and $5=$ daily). Cross-DG interactions for both bureaucracies were measured using ordinal logistic regression models (results available on request). We used translators as the reference category of employee, since they perform a process-based task and therefore could be expected to interact infrequently with colleagues beyond their units. The results show that, in both organisations, all employees, whatever their tasks, are more likely than translators to have contacts with other DGs in the organisation. Employees engaged in purpose-based tasks across DGs are not significantly different in their propensity to have contacts with other DGs.

However, we are not only interested in gauging the overall patterns of interaction across the organisations. We are also concerned with the respective positions of employees and organisational departments in the bipartite network of their relations, to identify silos. To this purpose, we rely on statistical blockmodelling. A blockmodel consists of a mapping of actors into blocks or positions and a statement regarding the relations between the positions (Faust and Wasserman, 1992). Widely used in the sociological literature on organisations (White, Boorman et al. 1976, Snyder and Kick 1979, Gerlach 1992), blockmodelling is a technique of positional analysis. Our data is bipartite, since the rows and the columns of the matrix describing the communication networks of, respectively, the Commission and the GSC are of different types: the rows are the employees; the columns are the different departments within each organization. In a bipartite network, ties can only exist between nodes of different types.

In positional analysis, actors are described in terms of their relations to other actors in sociomatrices, which are based on a concept of positional equivalence: actors are said to be regularly 
equivalent if they have equivalent ties to equivalent others (White and Reitz 1983). In a blockmodel, partitions of the set of the actors into a set of positions are sought such that actors who are regularly equivalent (i.e. have similar patterns of contact with, in this case, organisational departments) are assigned to the same positions. Robins, Bates et al. (2011) have used blockmodels to explore the connection between actors' responsibilities and their interaction patterns using a two-step procedure: first they performed a cluster analysis of actors' responsibilities, then used exploratory blockmodelling to identify network roles. In contrast, we use statistical blockmodelling to model the nature of the interaction, for both respondents and organizational units, and test whether these are based on the distinction between process and purpose tasks.

Statistical blockmodelling assumes that the probability of links between node sets can be modelled by a parameterized distribution (Wyse, Friel et al. 2017). The latent blockmodelling method used returns the number of groups that maximizes a Bayesian information criterion based on the complete data likelihood (Keribin, Brault et al. 2015, Wyse, Friel et al. 2017). The assumption is that connections patterns are observed manifestations of unobserved (or latent) features. We might observe blocks populated by employees with no or rare contacts with other parts of the organisation. If these blocks are populated by employees performing policy-related tasks, then silos exist, confirming our first hypothesis.

The blockmodelling analysis also reveals the clustering of organisational departments based on reported ties by employees. If silos exist, we should observe that policy DGs report limited or no ties from individual employees with policy-related tasks, while central and coordinating services such as the Legal Service, should report many ties from all employees. The political level is presumably furthest away from all but higher-level management. Co-workers are plausibly the main regular contact for all respondents, including siloed ones. In other words, 
employees and DGs with process-based tasks should emerge as the linchpins of the organisation, spanning through departments as they fulfil their tasks. Further, according to $\mathrm{H} 2$, we shall expect silos to be more pronounced within the (large policy-making organisation) European Commission than within the GSC (a small support organisation).

\section{Analysis and results}

The R Package 'blockmodels' is used for the analyses (Leger 2016). Membership in blocks is stochastic. We use a 0.5 probability threshold for inclusion into blocks for both the Commission and the Council Secretariat.

\section{The Council Secretariat and the Commission: internal contacts}

Taking the GSC first, Figure 1 reports the block structure and the correspondence between rows and columns, showing how work-related contacts between GSC respondents and 12 possible departments can be re-organized into a three-by-four matrix (the three clusters of rows and four clusters of columns). We provide visualisations of the permutations operated by blockmodelling in appendix Figures 1a and 2a.

A block is formed by the intersection between each row cluster and each column cluster. Rows are survey respondents, columns are the units of the organization (see Table 1 in appendix). Darker shading indicates higher frequency of contact; lighter shading indicates lower frequency of contact; white (or blank) indicates absence of contact. Each row cluster comprises employees showing similar frequency of communication with each column cluster. Column clusters comprise sub-groups of departments within each organization, with which different clusters of employees tend to have similar frequency of communication. 


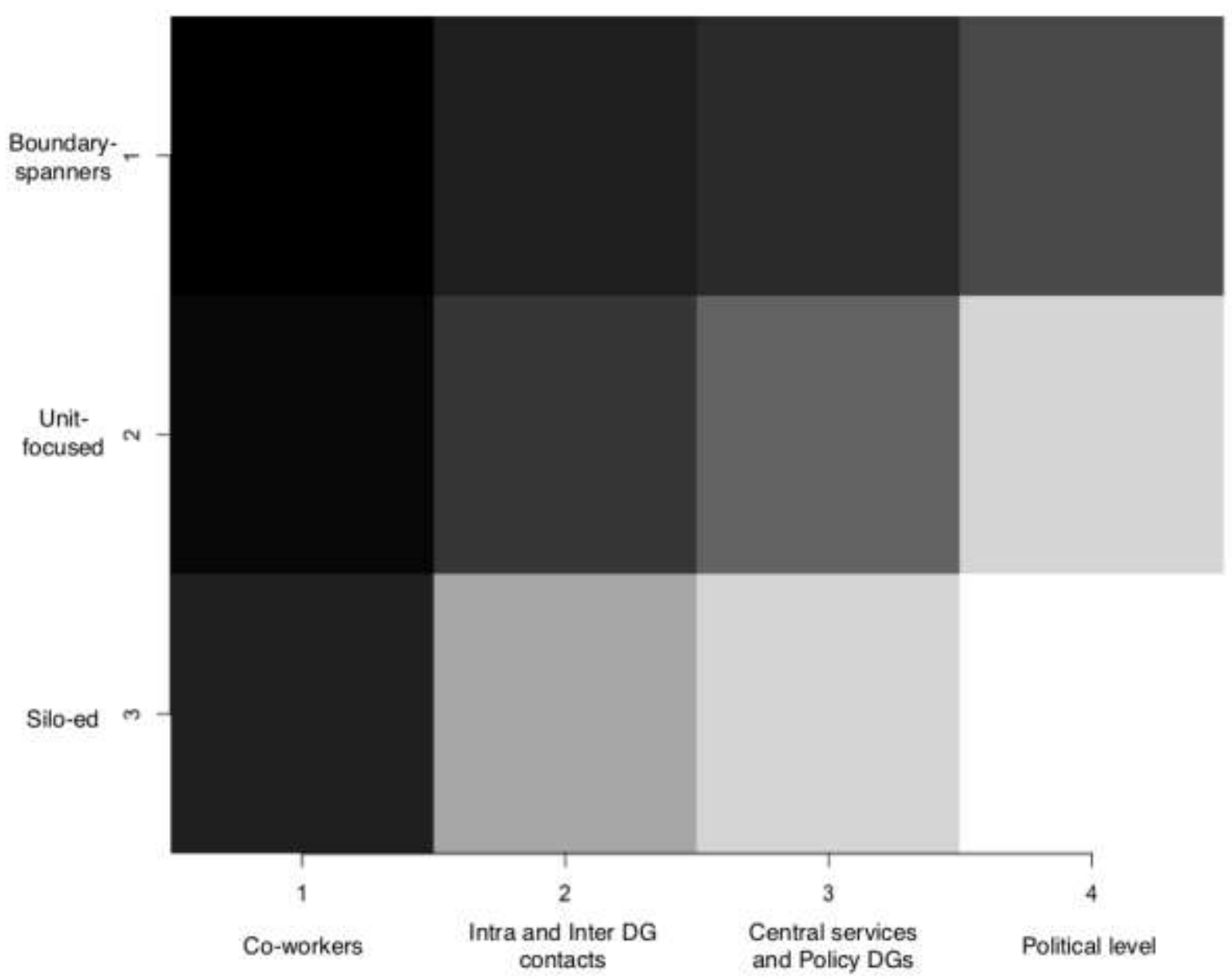

Equivalent employees tend to interact with equivalent departments. The clusters in the columns reveal which the latter are. We find that the column clusters comprise departments according to the nature of their tasks, and labelled them accordingly.

Column cluster 1: Co-workers - Colleagues in my unit other than my head of unit, My line manager, Colleagues in my directorate outside my unit;

Column cluster 2: Intra and inter DG - Colleagues in my DG outside my directorate, Colleagues in other DGs in the GSC (admin); 
Column cluster 3: Central services or policy DGs - Legal Service, Media and Communication, Document Management and other DGs in the GSC (policy);

Column cluster 2: Political level - Secretary General or private office of the Secretary General, Colleagues in GIP, President of the European Council and private office.

The three clusters of rows comprise $95 \%$ of our respondents from the GSC and depict three different types of employees. The first row describes employees who have daily contacts with their most immediate co-workers, weekly intra and inter DG contacts, monthly contacts with central services or policy DGs and who interact with the political level in the GSC several times a year. We define this category of employees as 'boundary-spanners' (Goerdel, 2006) as they maintain frequent relations across the whole bureaucracy (Bacharach and Aiken 1977). Just over one-third (35\%) of GSC respondents belongs to this cluster. These respondents are at the core of the communication flows in the bipartite network of professional relationships within the GSC.

The second row comprises the highest number of respondents $(42 \%)$. Members of this cluster have daily contacts with their co-workers, monthly contacts with colleagues in other DGs, and interact with central services several times a year, and with political units annually. Although they exhibit fewer regular contacts across the board than boundary-spanners, these employees communicate, albeit progressively less frequently, with progressively more hierarchically distant departments. We define this category of employees as 'unit-focused'.

The third and least numerous cluster (18\%) comprises respondents who have weekly contacts with their most immediate co-workers but rare contacts with any other counterpart. We see them as closest to the idea of siloed employees. 
Turning to the European Commission, the block structure was optimised for 9 groups, (see Figure 2), where work-related contacts between respondents and 11 possible departments are summarised by 20 blocks, a five by four matrix. With respect to the columns (i.e. the contacts), the groupings mirror the GSC's:

Column cluster 1: Intra and inter DG - Colleagues in my Directorate General outside my Directorate and Colleagues in other Directorates General;

Column cluster 2: Co-workers - colleagues in my unit other than the Head of Unit, my Head of Unit or deputy Head of Unit, colleagues in my directorate inside my unit;

Column cluster 3: Coordinating level - legal service, Secretariat General, members of my cabinet;

Column cluster 4: Political level - my Commissioner, other Commissioners, Members of other Cabinets.

The groups of staff, instead, differ from the GSC's groups. The overwhelming majority of Commission staff belong to two row clusters: the second, which comprises $46 \%$ of the respondents, and the fourth, comprising 39\%. They have daily contact with their co-workers only. Cluster 2 (the biggest overall) also has weekly contacts with other members of their DG and with other DGs, while respondents in cluster 2 have only monthly contacts with these colleagues. Frequency of contact is lowest between these row clusters and political and central services. Respondents in cluster 2 are termed 'Collaborative' - because they do not span boundaries across the whole organisation, but do branch out of their departments - and respondents in cluster 4 'Unit-focused'. Three additional clusters of employees are identified: two comprise only a few dozen individuals; another comprises $7 \%$ of the respondents. 


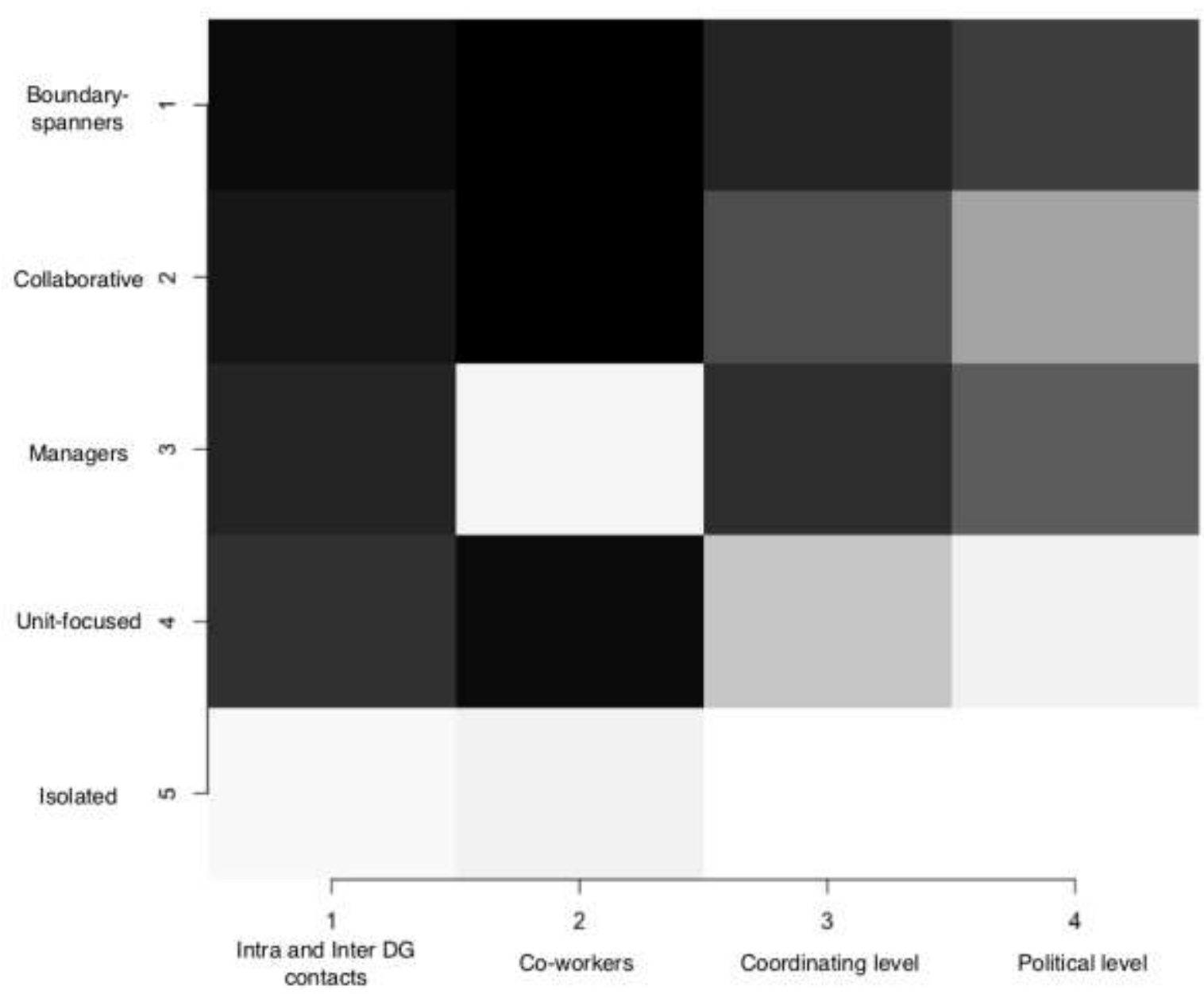

Respondents in row 1 are 'boundary-spanners' (Goerdel 2006), since they are frequently in contact with units across the whole of the organization. There are very few respondents in rows 3 and 5. In particular, row 3 respondents appear as interacting across units of the Commission but not with co-workers, whereas, those in row 5 do not have regular contact with anyone; hence, we label them 'isolates'.

We then investigate the composition of the rows in terms of the tasks that respondents perform. In the GSC, a majority of respondents are translators, followed by personnel with planning and organisational duties, while in the Commission a majority have policy, analysis and advice 
functions, followed by translation (see figures 5 and 6 in the appendix). In line with our argument, we observe a task-based pattern. In the GSC, employees with planning and coordination duties, as well as those with support roles, are shown very clearly to be 'boundary spanners' (see figure 7 in the appendix). Very few respondents report policy advice as their main activity. It is noticeable that none appears to be siloed. The second and third clusters of employees mostly comprise translators.

In the Commission, patterns of interaction are more complex and differentiated than described in existing scholarship (see figure 8 in the appendix). As expected, boundary-spanners are employees with process-based tasks (e.g. external relations and management), but also, contrary to $\mathrm{H} 1$, with purpose-based tasks (e.g. policy analysis and advice). Unit-focused personnel work on translation tasks, or in scientific research. Collaborative individuals mostly comprise staff who provide policy or legal advice and are employed in policy DGs. Respondents reporting very low levels of interaction with co-workers, but frequent interaction across the organization, are primarily located amongst those with managerial responsibilities. The isolates number four only, and are not discussed here.

Finally, in order to bridge between the individual and the organisational level of analysis, we traced individual employees to their DGs in both organisations. The results are in figures 9 and 10 in the online appendix. The figures show that employees belonging to the boundaryspanning and collaborative blocks belong to policy DGs, whereas more isolated employees belong to what we may define as process-based DGs, e.g. translation services, scientific research.

\section{Discussion of the results}


The aim of this research is to provide a diagnostic framework for the existence of silos in public bureaucracies, using the Commission and the GSC as case studies. Although both are part of the EU civil service, they differ in key respects. While the Commission is a 'policy machine', the Council Secretariat was described by one GSC official as 'a mega conference facility and facilitator of negotiations' (cited in Connolly et al 2017, p 31). The Commission's workforce, moreover, is ten times the size of the GSC's. Nonetheless, important similarities in the patterns of interaction within the two organizations emerge from the analysis, as well as significant differences.

Similarities are evident in terms of the frequency with which staff in both organizations interact not only with co-workers in their units or directorates, but with colleagues outside their immediate teams. Overall, the percentage of 'boundary spanners', with frequent contact across the organization, far outnumbers employees who are siloed or isolated in either organisation. Moreover, the existence and frequency of an individual's contacts in both organizations is associated with the tasks they undertake.

The majority of respondents with purpose-based tasks (e.g. providing policy analysis and advice) appear as boundary-spanners or as highly collaborative, a finding which contradicts H1. The only employees that cluster together as having infrequent or no contacts beyond their unit - our condition for being defined as 'siloed' - are translators. As expected, contacts with the upper echelons of both organisations (the 'political' and the 'coordinating' level) is more limited for all employees. This pattern is suggestive of functional differentiation of contacts (Page 2005, Peters 2015), rather than of siloing.

Therefore, the level of interaction between individuals in different parts of the organisation varies according to the function of the department in which they work - this lends support to our functionalist argument that traces job task to interaction patterns. The results challenge the 
image of the Commission as fragmented in silos (Trondal 2017) and support the more recent portrayal of the organization as integrated and coherent (Kassim et al 2013). Even if some individuals in policy DGs prioritise their own policy agenda and frame their objectives accordingly (Trondal 2011), it does not follow that they do not interact with other DGs; to the contrary, agenda-setting strategies foster communication across DGs (Hartlapp et al 2014). Individual employees who appear siloed perform tasks which although essential to the organization -- do not depend on their frequent interaction with other departments (e.g. translators). Therefore, the very limited incidence of siloed behaviour that we observe is not mission critical or likely to undermine organisational effectiveness.

The results also lend support to our second hypothesis, which stressed the importance of organisational mission and size on the overall communication patterns within bureaucracies: overall, the Commission (a larger, purpose-based organisation) emerges as a less integrated organization than the GSC (smaller and process-based).

\section{Conclusion}

The claim that silos are an endemic feature of bureaucracies has rarely been submitted to scrutiny. This article is intended to start a conversation concerning the appropriate theoretical conceptualization and empirical assessment of administrative silos. The 'silos' metaphor has travelled a considerable distance from its original invocation as a metaphor to highlight the breakdown of communication between units to virtually any organisation where internal differentiation is pronounced. We argue that the initial sense of the term needs to be recovered and restored if the concept is to retain its analytical value. Accordingly, we propose a return to the term's original usage -- namely, to refer to insular sub-systems or units, which have become isolated and separate from other parts of the organisation or system - rather than the current 
tendency to employ it as a synonym for the presence of organizational boundaries (Gregory 2006).

This article proposes a functionalist approach to the study of silos, which focuses on task at both individual and organisational level and links task to expected interaction patterns across the organisation. From Gulick (1937), we distinguish between purpose and process based tasks in order to focus our investigation on those employees whose silo-ization is problematic, rather than assuming uncritically that all employees in any bureaucratic organisation should constantly interact with all others (Page 2005). We also distinguish between purpose and process at organisational level because organisational characteristics are likely to affect incentives and necessity for interaction across different parts of the bureaucracy.

We also contend that the presence of silos in an organization or system is an empirical question. The existence of silos cannot be assumed or deduced from the mere existence of organizational boundaries. In most circumstances as earlier sub-literatures on bureaucratic politics, turf battles, and coordination suggested, boundaries can be negotiated. Differentiating silos from permeable intra-organisational boundaries and providing a test for detecting their existence will make it possible to act when organisational performance is jeopardised by their presence.

The article aims furthermore to make a methodological contribution to the literature. A diagnostic tool for detecting silos has not so far emerged in the public administration scholarship, to our knowledge. To fill this gap, we propose blockmodelling, which allows testing hypotheses concerning the generative mechanisms responsible for the observed network structure by reducing it to classes of equivalent relationships. Our hypotheses provide a roadmap of wider applicability to administrative organisations willing to assess the extent and the frequency of communication occurring within and across their departments. Moreover, 
the analysis of individual-level interaction offers a new approach beyond the traditional focus on departments or units.

Last but not least, the above analysis offers new insights on the EU civil service. In the case of the Commission, the analysis supports the picture of a more coherent and less fragmented organization than the classic image of it as compartmentalised. Moreover, results from a comparison with the GSC support the hypothesis that expected levels of interaction are likely to vary according to the size and mission of an organization.

Our parsimonious framework of investigation that can be expanded or amended through further inquiry and inclusion of more variables. Approaches that take into account socialisation effects based, for instance, on shared nationality or previous experiences of collaboration could provide an avenue of future enquiry. Moreover, gathering data on different types of interactions across employees and departments could further advance understanding of the structure of communication within bureaucracies. Finally, sources of poor performance or delivery other than the existence of silos could usefully be explored. Potential causes include scarce resources, multiple veto players, and indecision on the part of decision makers at the top of the organisation. In short, a rich research agenda exists for the exploration of internal interaction as it actually takes place across organisational boundaries.

Supporting data and materials for this article can be accessed from the Harvard Dataverse at the link https://dataverse.harvard.edu/dataset.xhtml?persistentId=doi:10.7910/DVN/M4DWZ3. 
Francesca Pia Vantaggiato is Lecturer in Public Policy at King's College London (UK)

Hussein Kassim is Professor of Politics at University of East Anglia (Norwich, UK)

Sara Connolly is Professor of Personnel Economics at University of East Anglia (Norwich, $\mathrm{UK})$

Address for correspondence: francesca.vantaggiato@kcl.ac.uk

Acknowledgements: The authors would like to thank the three anonymous reviewers and the editor for their constructive feedback, which greatly improved the paper. The authors would like to express our gratitude to staff in the two organisations who completed the survey or who agreed to be interviewed as part of the research for the two projects, 'European Commission: Facing the Future', and 'Understanding the EU Civil Service', on which this article is based. We greatly appreciate their willingness to share their experience with us and the time taken. We are most grateful to the members of the research team, especially Michael W. Bauer, Renaud Dehousse, Brigid Laffan, and Andrew Thompson, as well as to Vanessa Buth, Nick Wright, Henry Allen, Helen Fitzhugh, Suzanne Doyle, Timea Suli, Graeme Crouch, Luke Jackson, Antoine Mandret and Pippa Lacey, for their very considerable contributions to one or both projects, and especially to Dr David G Knott and Françoise Girard, the European University Institute, the German University of Administrative Sciences Speyer, and the University of East Anglia for providing the funding which enabled us to undertake the research. We thank our fellow panelists at the EUSA 17th biennial conference in Miami for useful insights. 
${ }^{\mathbf{i}}$ Administrators (ADRs) represent the largest staff category in the Commission, accounting for over $40 \%$ of personnel. Administrators are generally involved in drafting policies, analysis or advice, though translators and interpreters are also recruited as ADRs. Just under $30 \%$ of staff are assistants (ASTs), who perform an executive or technical role. Other staff are engaged as contract agents or are recruited locally.

${ }^{\text {ii }}$ For more information see shorturl.at/jlzU8 


\section{References}

Bach, T. and K. Wegrich (2019). The Blind Spots of Public Bureaucracy and the Politics of Non-Coordination. Cham, Switzerland, Palgrave Macmillan.

Bannister, F. and Connolly, R. (2012) 'Forward to the past: Lessons for the future of egovernment from the story so far', Innovation and the Public Sector, 17(3,4): 211-226.

Blau, P. M. (1970). "A formal theory of differentiation in organizations." American sociological review: 201-218.

Blau, P. M. (1972). "Interdependence and hierarchy in organizations." Social Science Research 1(1): $1-24$.

Blau, P. M. and R. A. Schoenherr (1971). The structure of organizations, New York, Basic Books.

Borgatti, S. P. and D. S. Halgin (2011). "Analyzing affiliation networks." The Sage handbook of social network analysis 1: 417-433.

Borgatti, S. P. and M. G. Everett (1992). "Notions of position in social network analysis." Sociological methodology: 1-35.

Bouckaert, G., B. G. Peters and K. Verhoest (2010). The Coordination of Public Sector Organizations: Shifting Patterns of Public Management, Basingstoke, UK, Palgrave Macmillan UK.

Bundred, S. (2006) 'Solutions to Silos: Joining Up Knowledge', Public Money and Management, 26(2): 125-130. 
Christensen, T. and P. Lægreid (2006). Autonomy and Regulation: Coping with Agencies in the Modern State, Cheltenham, UK, Edward Elgar Publishing Limited.

Christensen, T. and P. Lægreid (2007). "The Whole-of-Government Approach to Public Sector Reform." Public Administration Review 67(6): 1059-1066.

Christiansen, T. (2002). "Out of the shadows: The general secretariat of the Council of Ministers." The Journal of Legislative Studies 8(4): 80-97.

Cini, M. (1996). The European Commission: leadership, organisation, and culture in the EU administration, Manchester, UK, Manchester University Press.

Coase, R.H. (1937) 'The Nature of the Firm', Economica, 4(16): 386-405.

Connolly, S., Kassim, H. and Vantaggiato, F.P. (2017) "Understanding the EU Civil Service: The General Secretariat of the Council.”, General Secretariat of the Council.

Coombes, D. L. (1970). Politics and bureaucracy in the European Community: a portrait of the Commission of the EEC. London, UK, Sage.

Cram, L. (1994). "The European commission as a multi-organization: Social policy and IT policy in the EU." Journal of European public policy 1(2): 195-217.

Downs, A. (1967). Inside bureaucracy, Boston, USA, Little, Brown Inc.

Dunleavy, P. (1991). Democracy, bureaucracy and public choice: economic explanations in political science, Hemel Hempstead, UK, Harvester Wheatsheaf. 
Enemark, D., M. D. McCubbins and N. Weller (2014). "Knowledge and networks: An experimental test of how network knowledge affects coordination." Social Networks 36: 122133.

Egeberg, M. and J. Trondal (2016). "Why Strong Coordination at one Level of Government is Incompatible with Strong Coordination across Levels (and how to live with it): the Case of the European Union.” Public Administration, 94: 579-592.

Everett, M. G. and S. P. Borgatti (2013). "The dual-projection approach for two-mode networks." Social Networks 35(2): 204-210.

Faust, K. and S. Wasserman (1992). "Blockmodels: Interpretation and evaluation." Social networks 14(1-2): 5-61.

Froy, F. and S. Giguère (2008). Breaking out of silos: joining up policy locally. Working paper, OECD.

Gerlach, M. L. (1992). "The Japanese corporate network: A blockmodel analysis." Administrative Science Quarterly: 105-139.

Gregory, R. (2006). “Theoretical Faith and Practical Works: De-Autonomizing and JoiningUp in the New Zealand State Sector." Autonomy and Regulation. Coping with Agencies in the Modern State. T. Christensen and P. Laegreid. Cheltenham, UK, Edward Elgar Publishing Limited:137-159.

Gulick, L. H. (1937). Notes on the Theory of Organization. Papers on the Science of Administration. New York, Institute of Public Administration: 3-45. 
Hammond, T. H. (1990). "In Defence of Luther Gulick's' Notes on the Theory of Organization." Public Administration 68(2): 143-173.

Hartlapp, M., J. Metz and C. Rauh (2014). Which policy for Europe?: power and conflict inside the European Commission, Oxford, UK, Oxford University Press.

Hayes-Renshaw, F. and H. Wallace (2006). The Council of Ministers, Cham, Switzerland, Palgrave Macmillan.

Heims, E. M. (2019). Why Cooperation Between Agencies is (Sometimes) Possible: Turf Protection as Enabler of Regulatory Cooperation in the European Union. The Blind Spots of Public Bureaucracy and the Politics of Non-Coordination. T. Bach and K. Wegrich. Cham, Switzerland, Palgrave Macmillan.

Hood, C. (1974). "Administrative Diseases: Some Types of Dysfunctionality in Administration." Public Administration 52(4): 439-454.

Kassim, H. (2012). The Presidents and Presidency of the European Commission. The Oxford Handbook of the European Union. E. Jones, A. Menon and S. Weatherill. Oxford, UK, Oxford University Press: 219-232.

Kassim, H., J. Peterson, M. W. Bauer, S. Connolly, R. Dehousse, L. Hooghe and A. Thompson (2013). The European Commission of the twenty-first century, Oxford, UK, Oxford University Press.

Kassim, H., S. Connolly, R. Dehousse, O. Rozenberg and S. Bendjaballah (2016). "Managing the house: The presidency, agenda control and policy activism in the European Commission." Journal of European Public Policy 24(5): 1-22. 
Keribin, C., V. Brault, G. Celeux and G. Govaert (2015). "Estimation and selection for the latent block model on categorical data." Statistics and Computing 25(6): 1201-1216.

Lægreid, P., K. Sarapuu, L. Rykkja and T. Randma-Liiv (2016). Organizing for Coordination in the Public Sector: Practices and Lessons from 12 European Countries, Cheltenham, UK, Palgrave Macmillan UK.

Niskanen, W. A. (1971). Bureaucracy and representative government, Chicago, USA, Transaction Publishers.

O'Flynn, J., D. Blackman and J. Halligan (2013). Crossing Boundaries in Public Management and Policy: The International Experience, Oxon, UK, Routledge.

Page, E. (2005). Joined-Up Government and the Civil Service. Joined-Up Government. V. Bogdanor. Oxford, UK, Oxford University Press: 139-155.

Peters, B. G. (2015). Pursuing horizontal management: The politics of public sector coordination, Lawrence, USA, University Press of Kansas.

Peters, B. G. (2018). "The challenge of policy coordination." Policy Design and Practice, 1(1): $1-11$.

Peterson, J. (1995). "Policy networks and European Union policy making: a reply to Kassim." West European Politics 18(2): 389-407.

Pressman, J.L. and Wildavsky, A.B. (1973) Implementation How Great Expectations in Washington Are Dashed in Oakland; Or, Why It's Amazing that Federal Programs Work at All, Berkeley, USA, University of California Press. 
Rayner, J. and Howlett, M. (2009) 'Introduction: Understanding integrated policy strategies and their evolution', Policy and Society, 28(2): 99-109

Rhodes, R. A. W. (1994). "The hollowing out of the state: the changing nature of the public service in Britain." The Political Quarterly 65(2): 138-151.

Richards, D. and Smith, M.J. (2006) 'The Tensions of Political Control and Administrative Autonomy: from NPM to a Reconstituted Westminster Model' in T. Christensen and P Laegreid (eds.) Autonomy and Regulation: Coping with Agencies in the Modern State, London, Edward Elgar Publishing Limited: 181-200.

Robins, G., L. Bates and P. Pattison (2011). "Network governance and environmental management: conflict and cooperation." Public Administration 89(4): 1293-1313.

Sartori, G. (1970) 'Concept Misformation in Comparative Politics', The American Political Science Review, 64(4): 1033-1053

Seidman, H. (1997) Politics, Position, and Power. The Dynamics of Federal Organization, Oxford, UK, Oxford University Press, $5^{\text {th }}$ edition.

Thompson, J. D. (1967). Organizations in action: social science bases of administrative theory, New York, USA, McGraw-Hill.

Tett, G. (2015). The Silo Effect. New York, Simon \& Schuster.

Trondal, J. (2011). "Bureaucratic structure and administrative behaviour: lessons from international bureaucracies." West European Politics 34(4): 795-818.

Trondal, J. (2012). "On bureaucratic centre formation in government institutions: lessons from the European Commission." International Review of Administrative Sciences 78(3): 425-446. 
Trondal, J. (2017). "The rise of independent supranational administration: the case of the European Union administration.” The Rise of Common Political Order: Institutions, Public Administration and Transnational Space. J. Trondal. Cheltenham, UK, Edward Elgar Publishing Limited: 69-91.

Van de Ven, A. H. and W. Gordon (1984). "The Dynamics of Interorganizational Coordination." Administrative Science Quarterly 29(4): 598-621.

Vince, J. (2015) 'Integrated policy approaches and policy failure: the case of Australia's Oceans Policy', Policy Sciences, 48(2): 159-180

White, D. R. and K. P. Reitz (1983). "Graph and semigroup homomorphisms on networks of relations." Social Networks 5(2): 193-234.

White, H. C., S. A. Boorman and R. L. Breiger (1976). "Social Structure from Multiple Networks. I. Blockmodels of Roles and Positions." American Journal of Sociology 81(4): 730780.

Wyse, J., N. Friel and P. Latouche (2017). "Inferring structure in bipartite networks using the latent blockmodel and exact ICL." Network Science 5(1): 45-69. 